Short Communication

\title{
Extremely low frequency magnetic field induces oxidative stress in mouse cerebellum
}

\author{
Li Y. Chu ${ }^{1^{*}}$, Jong H. Lee ${ }^{1^{*}}$, Yun S. Nam ${ }^{1}$, Yu J. Lee ${ }^{1,2}$, Won-Hee Park ${ }^{3}$, Byung-Cheon Lee ${ }^{4}$, \\ Daejin Kim ${ }^{5}$, Yoon H. Chung ${ }^{5}$ and Ji H. Jeong ${ }^{1}$ \\ ${ }^{1}$ Department of Pharmacology and Research Institute for Translational System Biomics, College of Medicine, Chung-Ang \\ University, 221 Heukseok-Dong, Dongjak-Gu, Seoul 156-756, South Korea \\ ${ }^{2}$ Graduate School of Clinical Pharmacy, Sookmyung Women's University, Seoul, South Korea \\ ${ }^{3}$ Laboratory of Hygienic Pharmacy, College of Pharmacy, Sookmyung Women's University, Seoul, South Korea \\ ${ }^{4}$ Ki Primo Research Laboratory, KAIST Institute Information Technology Convergence, Daejeon, South Korea \\ ${ }^{5}$ Department of Anatomy and Research Institute for Translational System Biomics, College of Medicine, Chung-Ang Univer- \\ sity, 221 Heukseok-Dong, Dongjak-Gu, Seoul 156-756, South Korea
}

\begin{abstract}
We have investigated whether extremely low frequency magnetic field (ELF-MF) induces lipid peroxidation and reactive oxygen species in mouse cerebellum. After exposure to $60 \mathrm{~Hz}$ ELF-MF at $2.3 \mathrm{mT}$ intensity for 3 hours, there was a significant increase in malondialdehyde level and hydroxyl radical. ELF-MF significantly induced concomitant increase in superoxide dismutase without alteration in glutathione peroxidase activity. While glutathione contents were not altered, ascorbic acid levels were significantly decreased by ELF-MF exposure. These results indicate that ELF-MF may induce oxidative stress in mouse cerebellum. However, the mechanism remains further to be characterized.
\end{abstract}

Key words: Extremely low frequency magnetic field — Lipid peroxidation - Hydroxyl radical - Superoxide dismutase - Ascorbic acid

Abbreviations: ELF-MF, extremely low frequency magnetic field; GPx, glutathione peroxidase; GSH, glutathione; GSSG, oxidized disulphide; MDA, malondialdehyde; ROS, reactive oxygen species; SOD, superoxide dismutase.

Escalating electrification makes humans commonly exposed to magnetic field including extremely low frequency magnetic field (ELF-MF), which is generally produced by power lines and many kinds of electric appliances. Not only

\footnotetext{
* These authors contributed equally to this work and share the first authorship.

Correspondence to: Yoon Hee Chung, Department of Anatomy and Research Institute for Translational System Biomics, College of Medicine, Chung-Ang University, 221 Heukseok-Dong, Dongjak$\mathrm{Gu}$, Seoul 156-756, South Korea

E-mail: yoonhee@cau.ac.kr

Ji Hoon Jeong, Department of Pharmacology and Research Institute for Translational System Biomics, College of Medicine, Chung-Ang University, 221 Heukseok-Dong, Dongjak-Gu, Seoul 156-756, South Korea

E-mail: jhjeong3@cau.ac.kr
}

experimental but also epidemiological data suggest that there is an association between ELF-MF exposure and biological systems (Sabo et al. 2002; Strasak et al. 2002). One of the mostly discussed contemporary problems is the increased incidence of certain types of tumor, particularly leukemia and brain cancer (Coble et al. 2009; Comba and Fazzo 2009; Maslanyj et al. 2009; Mee et al. 2009; Saito et al. 2010). Among these problems, critically important for human health is that of whether ELF-MF can induce oxidative stress.

Oxidative stress is a physiological condition, in which elevated amount of oxygen free radical species causes cellular damage and change vital functions. Excess oxygen free radicals induce lipid peroxidation, especially in brain, which is very vulnerable to free radical insults because it contains high concentrations of easily peroxidizable fatty acid (Poon et al. 2004; Silva-Adaya et al. 2008). Cerebellum is thought to be an important integration site in the CNS for motor 
coordination and certain types of learned motor behavior (Haines and Dietrichs 1989; Anderson and Steinmetz 1994). This region is one of a few sites in the CNS where the pattern of intrinsic connections is known in considerable detail. Oxidative stress in cerebellum may contribute to many kinds of diseases including cancer and neurodegenerative diseases (Chung et al. 2000; Salman et al. 2009).

Our working hypothesis is that ELF-MF can affect biological systems by induction of free radicals. It has been suggested that 50/60 Hz ELF-MF may prolong the lifetime of free radicals (Repacholi and Greenebaum 1999; Akdag et al. 2007) and increase their concentration in living cells (Jajte et al. 2002). The increased life span of free radical makes living system including brain susceptible to lipid peroxidation. It has been found that electric and magnetic fields can influence lipid peroxidation under certain experimental conditions (Harakawa et al. 2005), although reports on the subject are conflicting. To elucidate our working hypothesis, we investigate one of major lipid peroxidative markers, malondialdehyde (MDA), and antioxidant defense systems, such as superoxide dismutase (SOD), glutathione peroxidase (GPx), glutathione (GSH) and ascorbic acid in mouse cerebellum following exposure to $60 \mathrm{~Hz}$ ELF-MF at $2.3 \mathrm{mT}$ for 3 hours.

The experiments were performed on 20 male Balb/C mice. All mice were handled in accordance with National Institute of Health guidelines for the humane care of laboratory animals. Four to five week-old mice were maintained on a $12 / 12 \mathrm{~h} \mathrm{light/dark}$ cycle with diet and water available ad libitum and were adapted for 2 weeks to these conditions before the experiment. Mice were assigned into two groups (sham group, $n=10$; experimental group, $n=10$ ). The experimental group mice were exposed to $2.3 \mathrm{mT}, 60 \mathrm{~Hz}$ ELF-MF for 3 hours in the mouse cage. For the sham group, the similar experimental procedure was applied to the mice which are kept in the mouse cage identical to that for the exposed group and the ELF-MF generator was turned off. After ELF-MF exposure, the mice were lightly anesthetized with pentobarbital (30 $\mathrm{mg} / \mathrm{kg}$, i.p.). The brain regions of interest rapidly were removed, weighed to the nearest milligram, frozen rapidly in microcentrifuge tubes and stored at $-70^{\circ} \mathrm{C}$. The brain regions were fetched from the freezer on each experiment and the cerebellum was isolated and weighed.

Lipid peroxidation was ascertained by the formation of MDA which was estimated by the thiobarbituric acid (TBA) method (Bekerecioglu et al. 1998). Tissue was weighed (wet weight $10 \mathrm{mg}$ ) and homogenized in $0.5 \mathrm{ml}$ Tris $\mathrm{HCl}$ buffer (pH 7.4). Then, $3 \mathrm{ml} \mathrm{TBA} \mathrm{(0.75 \% ),} 2 \mathrm{ml}$ trichloroacetic acid (30\%), and $0.2 \mathrm{ml} 5 \mathrm{~mol} / \mathrm{l} \mathrm{HCl}$ were added to the homogenates. Tubes were placed in boiling water for $15 \mathrm{~min}$ and centrifuged at $3000 \mathrm{rpm}$ for $10 \mathrm{~min}$. The concentration of MDA in supernatant was then calculated from spectrophotometric readings at a wavelength of $535 \mathrm{~nm}$.
The production of hydroxyl radical was measured by assaying 2,3-dihydroxybenzoic acid (2,3-DHBA) and 2,5-dihydroxybenzoic acid (2,5-DHBA), using salicylic acid conjugation methods (Diez et al. 2001). All samples were sonicated in $0.1 \mathrm{~mol} / \mathrm{l}$ perchloric acid solution containing $10 \mathrm{nmol}$ dihydroxybenzylamine (DHBA) as an internal standard. The sonicated tissue was centrifuged at $13,000 \times g$ for $20 \mathrm{~min}$ and the supernatant $(20 \mu \mathrm{l})$ was injected into HPLC-ECD (High Pressure Liquid Performance-Electrochemical Detector). HPLC analysis system consisted of pump, column (Phenamenex LUNA C18, USA), detector (Model 840-EC, Jasco, Japan) and integrator. Mobile phase consisted of $0.75 \mathrm{mmol}$ otanesulforic acid, $0.07 \mathrm{~mol} / \mathrm{l}$ sodium phosphate monobasic and $0.1 \mathrm{mmol}$ EDTA in $12 \%$ methanol solution. The $\mathrm{pH}$ of the mobile phase was adjusted to 2.8 with perchloric acid and then degassed for $15 \mathrm{~min}$ in sonicator (Branson 3200, CT, USA). This system was run at flow rate $1 \mathrm{ml} / \mathrm{min}$ and the voltage applied to the electrodes set at $670 \mathrm{mV}$.

The SOD enzyme activity was measured according to the method described by Bellissimo et al. (2001) with slight modification. Cerebellum was homogenized in PBS $0.05 \mathrm{M}$ (pH 7.4) in buffer solution $(1 \mathrm{mg} / 5 \mu \mathrm{l})$. Each homogenate was centrifuged at $10,000 \times g\left(4^{\circ} \mathrm{C}\right)$ for $20 \mathrm{~min}$, and the supernatant was carefully separated. After homogenization, $20 \mu \mathrm{g}$ of cerebellum was mixed with $0.5 \mathrm{ml}$ of a solution composed by $0.05 \mathrm{~mol} / \mathrm{l}$ phosphate buffer (PBS), pH 7.0 containing hydroxylamine $(0.2 \mathrm{mmol} / \mathrm{l})$ and hypoxanthine $(0.2 \mathrm{mmol} / \mathrm{l})$. The reaction was started by addition of $1 \mathrm{ml}$ of a solution, composed by $1.25 \mathrm{mU} / \mathrm{ml}$ xanthine oxidase, $10^{-4} \mathrm{M}$ EDTA dissolved in $20.8 \mathrm{mmol} / \mathrm{l}$ potassium buffer, pH 7.0 and $\mathrm{Na}_{2} \mathrm{~B}_{4} \mathrm{O}_{7}(15 \mathrm{mmol} / \mathrm{l})$. This mixture was incubated for $20 \mathrm{~min}$ at $37^{\circ} \mathrm{C}$ without shaking. Finally, $1.0 \mathrm{ml}$ of the $\mathrm{N}$-1-naphthylethylenediamine (5 $\mu \mathrm{g} / \mathrm{ml})$ and sulfanilic acid ( $300 \mu \mathrm{g} / \mathrm{ml})$ diluted in $25 \%$ acetic acid was added. The final mixture was allowed to stand for $20 \mathrm{~min}$ at room temperature and the optical absorption was measured at $550 \mathrm{~nm}$. A unit of enzyme activity (U) is defined as the quantity of protein responsible for the inhibition of $50 \%$ of this reaction and the activity was expressed as $\mathrm{U} / \mathrm{mg}$ of protein.

The GPx activity was measured according to the method described by Bellissimo et al. (2001) with slight modification. Cerebellum was homogenized in PBS 0.05 M (pH 7.4) in buffer solution $(1 \mathrm{mg} / 5 \mu \mathrm{l})$. After homogenization, $30 \mu \mathrm{g}$ of protein was added to $500 \mu \mathrm{l}$ of PBS pH 7.0 containing $10^{-3} \mathrm{~mol} / \mathrm{l}$ reduced glutathione, 2 units of yeast glutathione reductase and $2 \times 10^{-4} \mathrm{NADPH}$. After $20 \mathrm{~min}$ at $37^{\circ} \mathrm{C}$, the reaction was initiated by the addition of t-butyl-GPx to a final concentration of $10^{-3} \mathrm{~mol} / \mathrm{l}$, under constant agitation. The oxidation of NADPH was calculated using extinction coefficient for NADPH of $6.22 \times 10^{3}$ at $340 \mathrm{~nm}$ and the reaction was made for $5 \mathrm{~min}$. One enzyme unit was defined as $1 \mu \mathrm{mol} / \mathrm{l} \mathrm{NADPH} / \mathrm{mU}$ per $\mathrm{mg}$ of protein. 
Glutathione level immediately was measured from dissected tissues using a minor modification of the method described by Reed et al. (1980). Briefly, each sample of the acidified supernatant was added to the internal standard ( $1 \mathrm{mmol} / \mathrm{l}$ cysteic acid) in $0.88 \mathrm{~mol} / \mathrm{l}$ iodoacetic acid. Excess sodium hydrogen carbonate was added to the reaction to precipitate sodium perchlorate. Subsequently, $0.5 \mathrm{ml}$ of an alcoholic solution of $1.5 \%(\mathrm{v} / \mathrm{v})$ 2,4-dinitrofluorobenzene was added to each sample, and the samples were incubated for $4 \mathrm{~h}$. Diethyl ether $(1.0 \mathrm{ml})$ was added, and the samples were shaken and centrifuged $(20 \mathrm{~min}, 2000 \times g$, room temperature). The residual aqueous phase containing derived glutathione was separated and analyzed by HPLC. The separation of 5-carboxymethyl glutathione was carried out at room temperature with a flow rate of $1.2 \mathrm{ml} / \mathrm{min}$. Chromatographic separation of derivatives was performed by injecting samples $(10 \mu \mathrm{l})$ of the aqueous phase onto a Spherisorb S-5 amino ODS column. Glutathione was subsequently detected using a UV detector at 365 $\mathrm{nm}$. Glutathione were quantified in relation to the internal standard (cysteic acid).

Ascorbic acid concentration $(\mathrm{mg} / \mathrm{dl})$ was measured by the photometric method. Ascorbic acid in sample was oxi- dized by $\mathrm{Cu}^{2+}$ to form dehydroascorbic aicd, which reacts with acidic 2,4-dinitrophenylhydrazine to form a red bishydrazone, which was measured at $520 \mathrm{~nm}$. Two hundred $\mu \mathrm{l}$ of freshly prepared methaphosphoric acid were added to sample $1 \mathrm{ml}$ and concentrated for $10 \mathrm{~min}$ at $2500 \mathrm{rpm}$. Two hundred microliters of dinitrophenylhydrazine-thiourea-copper sulfate (DTCS) reagent was added to $500 \mu \mathrm{l}$ of the clear supernatant, standard and blank. The tubes were incubated in a water bath at $37^{\circ} \mathrm{C}$ for $3 \mathrm{~h}$. After cooling $2 \mathrm{ml}$ of cold sulfuric acid ( $12 \mathrm{~mol} / \mathrm{l})$ was added. The absorbance at $520 \mathrm{~nm}$ was determined against the blank.

All data were expressed as mean \pm SEM. Statistical analysis was performed using unpaired t-test. Differences were considered significant when $p<0.05$.

As a marker for oxidative stress, we assayed MDA for lipid peroxidation and hydroxyl radical for production of reactive oxygen species (ROS) (Fig. 1). MDA level was significantly increased $(p<0.05)$ in the cerebellum of mouse exposed to $60 \mathrm{~Hz}$ ELF-MF for more than $3 \mathrm{~h}$ compared to sham group when mice were exposed to ELF-MF $(2.3 \mathrm{mT})$ for different times (1-5 h) (Fig. 1A). Therefore, we fixed the exposure period at $3 \mathrm{~h}$ in this study. Level of hydroxyl radical was assayed by quantifying 2,3-DHBA and 2,5-DHBA (Fig. 1B)

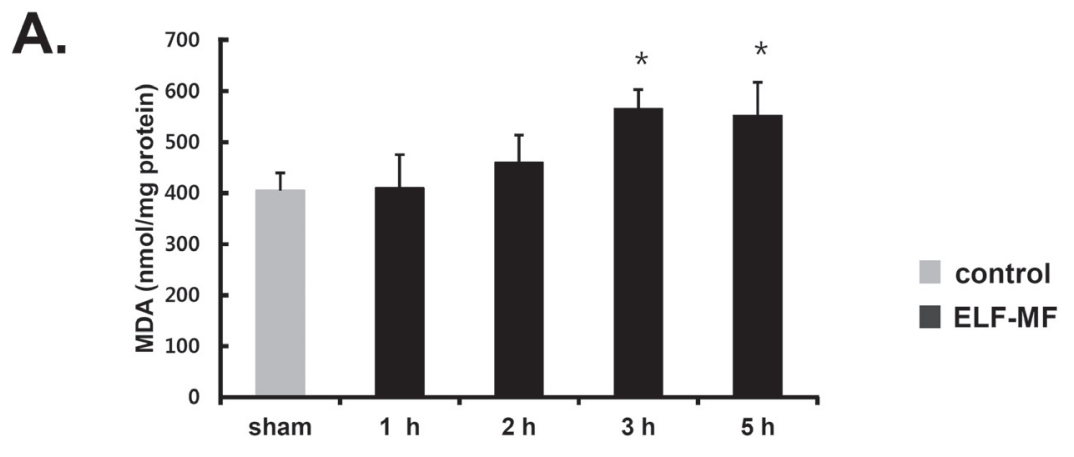

B.

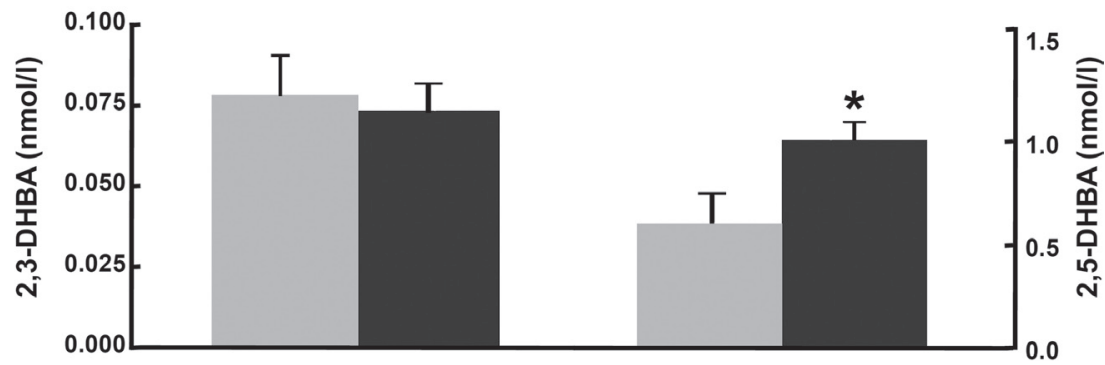

Figure 1. Effect of ELF-MF on production of MDA and hydroxyl radical in mouse cerebellum. A. Mice were exposed to $60 \mathrm{~Hz}$ ELFMF $(2.3 \mathrm{mT})$ for different times $(1 \mathrm{~h}-5 \mathrm{~h})$. MDA production was significantly increased in mouse cerebellum exposed to ELF-MF for $3 \mathrm{~h}$ compared to sham group. B. The production of hydroxyl radical was measured by assaying 2,3-dihydroxybenzoic acid (2,3-DHBA) and 2,5-dihydroxybenzoic acid (2,5-DHBA), using salicylic acid conjugation methods. After ELF-MF exposure, 2,5-DHBA level was significantly increased. Each column indicated the mean \pm SEM in seven to eight mice. ${ }^{*}$ indicates values which are significant from control group at $p<0.05$. ELF-MF, extremely low frequency magnetic field. 
using HPLC-ECD system after ELF-MF exposure. The exposure significantly raised the level of 2,5-DHBA $(p<0.05)$ but not 2,3-DHBA.

We also measured major enzymatic or non-enzymatic antioxidants in mouse cerebellum, including SOD, GPx, GSH and ascorbic acid. SOD and GPx activities were assayed to evaluate the effect of ELF-MF exposure on enzymatic defense systems against oxidative stress (Fig. 2). SOD activity was significantly increased in mouse cerebellum $(p<0.05)$, while there was no significant alteration in GPx activity (Fig. 2A). The alteration of GSH and ascorbic acid level after ELF-MF exposure was observed as non-enzymatic defense components. GSH contents were not significantly different from sham controls, but ascorbic acid levels were significantly decreased by exposure to $60 \mathrm{~Hz}$ ELF-MF for $3 \mathrm{~h}(p<0.05$, Fig. 2B).

Exposure to ELF-MF comes from many sources, like high voltage transmission lines and electric appliances such as TV monitors, radios, hair dryers and electric blankets, because sources with high voltage and strong currents produce strong electromagnetic fields. The strength of ELF-MF weak- ens with increasing distance from the source. In a survey of ELF-MF around almost different ELF-MF household appliances, weak levels from 0.03 to $2.9 \mu \mathrm{T}$ were measured in a typical user distance (Delpizzo 1990). However, the ELF-MF generating from transmission lines, transportation and industrial work-place was strong up to 0.1-50 mT (Stern 1987). The strength of ELF-MF we exposed to animals in this study was comparable to the occupational exposure predominant from working near industrial equipment using high currents.

This study clearly demonstrated that the levels of hydroxyl radical and MDA were significantly increased in mouse cerebellum following exposure to $60 \mathrm{~Hz}$ ELF-MF at $2.3 \mathrm{mT}$ for 3 hours. As enzymatic defense systems against oxidative stress, SOD activity was significantly increased in mouse cerebellum, while there was no significant alteration in GPx activity. Among non-enzymatic antioxidants, GSH contents were not significantly changed, but ascorbic acid levels were significantly decreased in ELF-MF-exposed mice.

Our biochemical data of MDA and hydroxyl radical measurement were consistent with our previous chemilu-
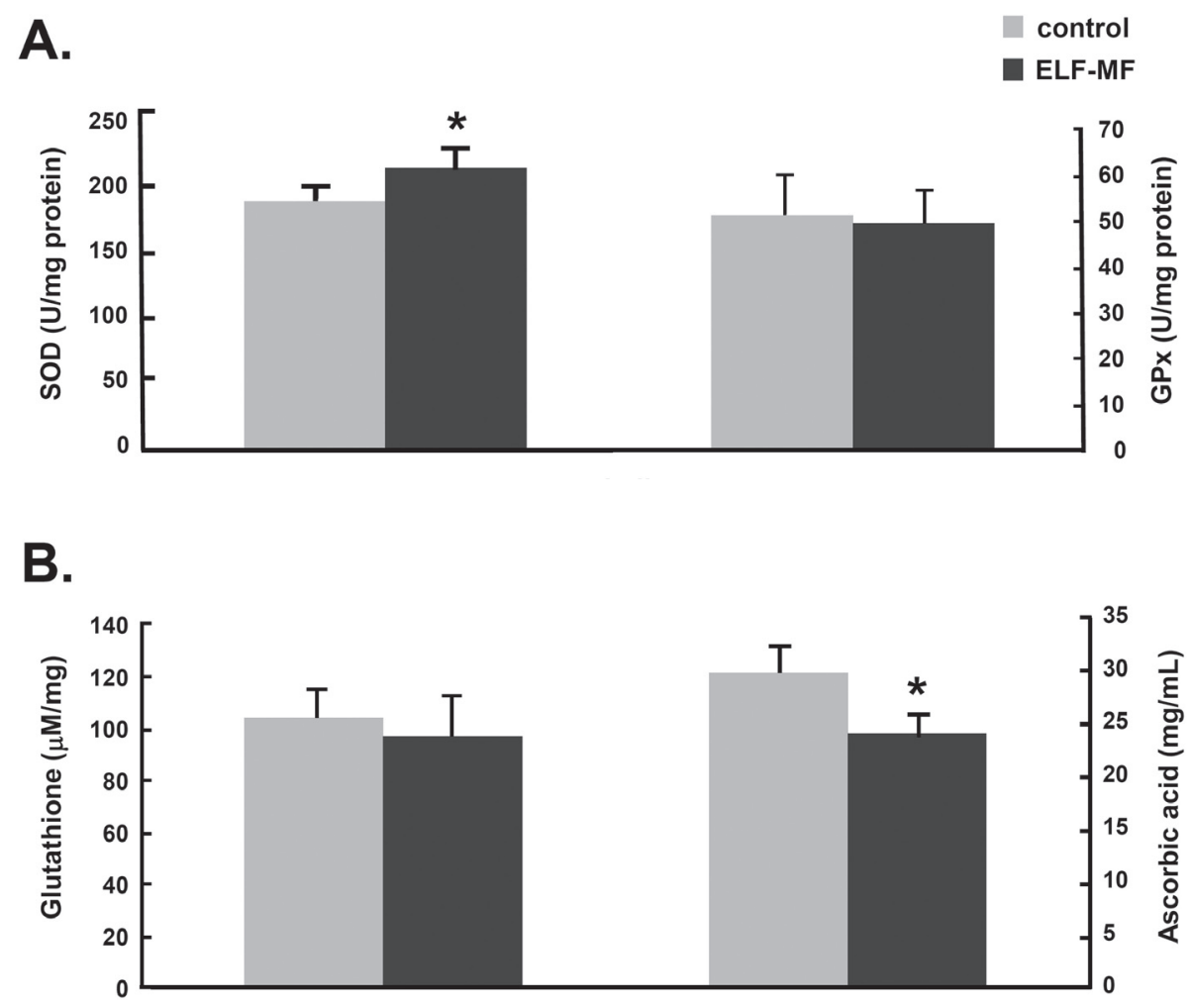

Figure 2. Effects of ELF-MF on enzymatic (A) and non-enzymatic (B) antioxidant activities in mouse cerebellum. The exposure to ELFMF significantly increased SOD activity in mouse cerebellum while it failed to change in GPx activity. There was a significant decrease in the level of ascorbic acid in cerebellum after ELF-MF while the level of glutathione was not altered. Each column indicates the mean \pm SEM of in seven to eight mice. ${ }^{\star}$ indicates values which are significant from control group at $p<0.05$. ELF-MF, extremely low frequency magnetic field; SOD, superoxide dismutase; GPx, glutathione peroxidase. 
minescence data (Lee et al. 2004). After exposure to ELFMF, MDA levels were increased in guinea pig liver tissue (Canseven et al. 2008) and the lipid peroxidative process and $\mathrm{H}_{2} \mathrm{O}_{2}$ concentration were slightly increased in heart tissue (Goraca et al. 2010). Especially, an increase in MDA level was found in rat brains exposed to long-term ELF-MF (Akdag et al. 2010). In addition, ELF-MF-enhanced cell proliferation was suppressed by radical scavengers (Katsir and Parola 1998), indicating that ELF-MF is involved with free radical reaction in organism. MF exposure indeed induced DNA degradation and potentiated the activity of oxidant radicals, which could be diminished by the presence of an antioxidant ( $\mathrm{Li}$ and Chow 2001). Combined with these previous findings, our observations have suggested that exposure to ELF-MF are among the effective conditions on the formation of free radicals and lipid peroxidation in mouse cerebellum.

Cells have developed an enzymatic antioxidant pathway against ROS which are generated during oxidative metabolism: firstly, the dismutation of superoxide anion $\left(\mathrm{O}_{2}^{-}\right)$to hydrogen peroxide $\left(\mathrm{H}_{2} \mathrm{O}_{2}\right)$ catalyzed by SOD; and secondly, the conversion of $\mathrm{H}_{2} \mathrm{O}_{2}$ to $\mathrm{H}_{2} \mathrm{O}$ by GPx or catalase (de Haan et al. 1995; Vazquez-Medina et al. 2006). Any increase in SOD catalytic activity produces an excess of $\mathrm{H}_{2} \mathrm{O}_{2}$ that must be efficiently neutralized by GPx. The activity of first and second step antioxidant enzymes must, therefore, be balanced to prevent oxidative damage in cells, which may contribute to various pathological processes (Sun and Chen 1998). Disequilibrium between SOD and GPx activity ratio could represent a marker of oxidative stress in cells (Mehta and Flora 2001). Therefore, an increased SOD activity in mouse cerebellum might represent an adaptive response to a higher superoxide ions production following exposure to $60 \mathrm{~Hz} \mathrm{MF}$.

Considering the roles of GPx as an antioxidant enzyme in oxidative stress, our results lead us to the hypothesis that where ELF-MF may act on the nonenzymatic defense system such as GSH. Although relatively resistant to 'spontaneous oxidation', GSH reacts rapidly and nonenzymatically with hydroxyl radical, and with dinitrogen trioxide $\left(\mathrm{N}_{2} \mathrm{O}_{3}\right)$ and peroxynitrite (Kurozumi et al. 2005). In addition to its action as a chemical antioxidant, GSH also acts in the enzymatic first line antioxidant defense as a co-factor in GPX-mediated reduction of peroxides, also resulting in formation of the oxidized disulphide, GSSG. No significant alteration of GSH by ELF-MF exposure has indicated that the chemical reaction requiring the electron transfer between ROS and GSH or its derivatives may not be influenced by ELF-MF stimuli.

Among non-enzymatic antioxidants, ascorbic acid levels were significantly decreased in ELF-MF-exposed group in this study. Recent studies also revealed that ascorbic acid acts against oxidative stress in the CNS (Rodriguez-Martinez et al. 2004; Zaidi and Banu 2004). Ascorbic acid served as an effective antioxidant against restraint stress induced pro-oxidant status and increased the anti-oxidant enzyme activity in rat brain (Zaidi and Banu 2004). It also decreased 3 -propionic acid-induced oxidative stress in rat brain (Rodriguez-Martinez et al. 2004). After exposure to ELF-MF, the levels of lipid peroxide in rats treated with ascorbic acid were lower than those in the sham group (Harakawa et al. 2005). The present findings indicated that decreased level of ascorbic acid might be involved in ELF-MF-induced lipid peroxidation.

This study has demonstrated that ELF-MF may be stimulus to be involved in free radical generation. The findings have also revealed that lipid peroxidation and antioxidant defense system such as SOD and ascorbic acid in the cerebellum was modulated by ELF-MF exposure. This is a meaningful observation for elucidation of molecular mechanism behind the process of ELF-MF in connection with oxidative stress. Further studies are needed to elucidate how ELF-MF can affect biological system in connection with oxidative stress.

Acknowledgements: This work was supported by the Korea Research Foundation Grant funded by the Korean Government (MOEHRD) (KRF-2007-531-E00058).

\section{References}

Akdag M. Z., Bilgin M. H., Dasdag S., Tumer C. (2007): Alteration of nitric oxide production in rats exposed to a prolonged, extremely low-frequency magnetic field. Electromagn. Biol. Med. 26, 99-106 http://dx.doi.org/10.1080/15368370701357866

Akdag M. Z., Dasdag S., Ulukaya E., Uzunlar A. K., Kurt M. A., Taşkin A. (2010): Effects of extremely low-frequency magnetic field on caspase activities and oxidative stress values in rat brain. Biol. Trace Elem. Res. 138, 238-249

http://dx.doi.org/10.1007/s12011-010-8615-3

Anderson B. J., Steinmetz J. E. (1994): Cerebellar and brainstem circuits involved in classical eyeblink conditioning. Rev. Neurosci. 5, 251-273

http://dx.doi.org/10.1515/REVNEURO.1994.5.3.251

Bekerecioglu M., Kutluhan A., Demirtas I., Karaayvaz M. (1998): Prevention of adriamycin-induced skin necrosis with various free radical scavengers. J. Surg. Res. 75, 61-65 http://dx.doi.org/10.1006/jsre.1997.5257

Bellissimo M. I., Amado D., Abdalla D. S., Ferreira E. C., Cavalheiro E. A., Naffah-Mazzacoratti M. G. (2001): Superoxide dismutase, glutathione peroxidase activities and the hydroperoxide concentration are modified in the hippocampus of epileptic rats. Epilepsy Res. 46, 121-128 http://dx.doi.org/10.1016/S0920-1211(01)00269-8

Canseven A. G., Coskun S., Seyhan N. (2008): Effects of various extremely low frequency magnetic fields on the free radical processes, natural antioxidant system, and respiratory burst 
system activities in the heart and liver tissues. Indian J. Biochem. Biophys. 45, 326-331

Chung Y. H., Shin C., Kim M. J., Lee B., Park K. H., Cha C. I. (2000): Immunocytochemical study on the distribution of p53 in the hippocampus and cerebellum of the aged rat. Brain Res. 885, 137-141 http://dx.doi.org/10.1016/S0006-8993(00)02979-6

Coble J. B., Dosemeci M., Stewart P. A., Blair A., Bowman J., Fine H. A., Shapiro W. R., Selker R. G., Loeffler J. S., Black P. M., Linet M. S., Inskip P. D. (2009): Occupational exposure to magnetic fields and the risk of brain tumors. Neuro. Oncol. 11, 242-249 http://dx.doi.org/10.1215/15228517-2009-002

Comba P., Fazzo L. (2009): Health effects of magnetic fields generated from power lines: new clues for an old puzzle. Ann. 1st Super Sanita 45, 233-237

Delpizzo, V. (1990): A model to assess personal exposure to ELF magnetic fields from common household sources. Bioelectromagnetics 11, 139-147 http://dx.doi.org/10.1002/bem.2250110205

Diez L., Livertoux M., Stark A., Wellman-Rousseau M., Leroy P. (2001): High-performance liquid chromatographic assay of hydroxyl free radical using salicylic acid hydroxylation during in vitro experiments involving thiols. J. Chromatogr. B Biomed. Sci. Appl. 763, 185-193 http://dx.doi.org/10.1016/S0378-4347(01)00396-6

Goraca A., Ciejka E., Piechota A. (2010): Effects of extremely low frequency magnetic field on the parameters of oxidative stress in heart. J. Physiol. Pharmacol. 61, 333-338

de Haan J. B., Cristiano F., Iannello R. C., Kola I. (1995): Cu/Znsuperoxide dismutase and glutathione peroxidase during aging. Biochem. Mol. Biol. Int. 35, 1281-1297

Haines D. E., Dietrichs E. (1989): Nonsomatic cerebullar circuits: a broader view of cerebellar involvements in locomotion. J. Mot. Behav. 21, 518-525

Harakawa S., Inoue N., Hori T., Tochio K., Kariya T., Takahashi K., Doge F., Suzuki H., Nagasawa H. (2005): Effects of a $50 \mathrm{~Hz}$ electric field on plasma lipid peroxide level and antioxidant activity in rats. Bioelectromagnetics 26, 589-594 http://dx.doi.org/10.1002/bem.20137

Jajte J., Grzegorczyk J., Zmyślony M., Rajkowska E. (2002): Effect of $7 \mathrm{mT}$ static magnetic field and iron ions on rat lymphocytes: apoptosis, necrosis and free radical processes. Bioelectrochemistry $\mathbf{5 7}, 107-111$ http://dx.doi.org/10.1016/S1567-5394(02)00059-2

Katsir G., Parola A. H. (1998): Enhanced proliferation caused by a low frequency weak magnetic field in chick embryo fibroblasts is suppressed by radical scavengers. Biochem. Biophys. Res. Commun. 252, 753-756 http://dx.doi.org/10.1006/bbrc.1998.9579

Kurozumi R., Takahashi M., Kojima S. (2005): Involvement of mitochondrial peroxynitrite in nitric oxide-induced glutathione synthesis. Biol. Pharm. Bull. 28, 779-785 http://dx.doi.org/10.1248/bpb.28.779

Lee B. C., Johng H. M., Lim J. K., Jeong J. H., Baik K. Y., Nam T. J., Lee J. H., Kim J., Sohn U. D., Yoon G., Shin S., Soh K. S. (2004): Effects of extremely low frequency magnetic field on the antioxidant defense system in mouse brain: a chemiluminescence study. J. Photochem. Photobiol. B 73, 43-48 http://dx.doi.org/10.1016/j.jphotobiol.2003.10.003

Li S. H., Chow K. C. (2001): Magnetic field exposure induces DNA degradation. Biochem. Biophys. Res. Commun. 280, $1385-1388$ http://dx.doi.org/10.1006/bbrc.2001.4286

Maslanyj M., Simpson J., Roman E., Schuz J. (2009): Power frequency magnetic fields and risk of childhood leukaemia: misclassification of exposure from the use of the distance from power line' exposure surrogate. Bioelectromagnetics 30, $183-188$ http://dx.doi.org/10.1002/bem.20465

Mee T., Whatmough P., Broad L., Dunn C., Maslanyj M., Allen S., Muir K., McKinney P. A., van Tongeren M. (2009): Occupational exposure of UK adults to extremely low frequency magnetic fields. Occup. Environ. Med. 66, 619-627 http://dx.doi.org/10.1136/oem.2008.040329

Mehta A., Flora S. J. (2001): Possible role of metal redistribution, hepatotoxicity and oxidative stress in chelating agents induced hepatic and renal metallothionein in rats. Food Chem. Toxicol. 39, 1029-1038 http://dx.doi.org/10.1016/S0278-6915(01)00046-1

Poon H. F., Calabrese V., Scapagnini G., Butterfield D. A. (2004): Free radicals: key to brain aging and heme oxygenase as a cellular response to oxidative stress. J. Gerontol. A Biol. Sci. Med. Sci. 59, 478-493 http://dx.doi.org/10.1093/gerona/59.5.M478

Reed D. J., Babson J. R., Beatty P. W., Brodie A. E., Ellis W. W., Potter D. W. (1980): High-performance liquid chromatography analysis of nanomole levels of glutathione, glutathione disulfide, and related thiols and disulfides. Anal. Biochem. 106, 55-62

http://dx.doi.org/10.1016/0003-2697(80)90118-9

Repacholi M. H., Greenebaum B. (1999): Interaction of static and extremely low frequency electric and magnetic fields with living systems: health effects and research needs. Bioelectromagnetics 20, $133-160$

http://dx.doi.org/10.1002/(SICI)1521-186X(1999)20:3<133:: AID-BEM1>3.0.CO;2-O

Rodriguez-Martinez E., Rugerio-Vargas C., Rodríguez A. I., Borgonio-Pérez G., Rivas-Arancibia S. (2004): Antioxidant effects of taurine, vitamin $\mathrm{C}$ and vitamin $\mathrm{E}$ on oxidative damage in hippocampus caused by the administration of 3-nitropropionic acid in rats. Int. J. Neurosci. 114, 1133-1145 http://dx.doi.org/10.1080/00207450490475959

Sabo J., Mirossay L., Horovcak L., Sarissky M., Mirossay A., Mojzis J. (2002): Effects of static magnetic field on human leukemic cell line HL-60. Bioelectrochemistry 56, 227-231 http://dx.doi.org/10.1016/S1567-5394(02)00027-0

Saito T., Nitta H., Kubo O., Yamamoto S., Yamaguchi N., Akiba S., Honda Y., Hagihara J., Isaka K., Ojima T., Nakamura Y., Mizoue T., Ito S., Eboshida A., Yamazaki S., Sokejima S., Kurokawa Y., Kabuto M. (2010): Power-frequency magnetic fields and childhood brain tumors: a case-control study in Japan. J. Epidemiol. 20, 54-61 http://dx.doi.org/10.2188/jea.JE20081017

Salman M. S., Marles S. L., Booth F. A., Del Bigio M. R. (2009): Early-onset neurodegenerative disease of the cerebellum and motor axons. Pediatr. Neurol. 40, 365-370 
http://dx.doi.org/10.1016/j.pediatrneurol.2008.11.020

Silva-Adaya D., Perez-De La Cruz V., Herrera-Mundo M. N., MendozaMacedo K., Villeda-Hernandez J., Binienda Z., Ali S. F., Santamaria A. (2008): Excitotoxic damage, disrupted energy metabolism, and oxidative stress in the rat brain: antioxidant and neuroprotective effects of L-carnitine. J. Neurochem. 105, 677-689 http://dx.doi.org/10.1111/j.1471-4159.2007.05174.x

Stern R. M. (1987): Cancer incidence among welders: possible effects of exposure to extremely low frequency electromagnetic radiation (ELF) and to welding fumes. Environ. Health Perspect. 76, 22-29 http://dx.doi.org/10.1289/ehp.8776221

Strasak L., Vetterl V., Smarda J. (2002): Effects of low-frequency magnetic fields on bacteria Escherichia coli. Bioelectrochemistry $\mathbf{5 5}, 161-164$
http://dx.doi.org/10.1016/S1567-5394(01)00152-9

Sun A. Y., Chen Y. M. (1998): Oxidative stress and neurodegenerative disorders. J. Biomed. Sci. 5, 401-414 http://dx.doi.org/10.1007/BF02255928

Vazquez-Medina J. P., Zenteno-Savin T., Elsner R. (2006): Antioxidant enzymes in ringed seal tissues: potential protection against dive-associated ischemia/reperfusion. Comp. Biochem. Physiol. C Toxicol. Pharmacol. 142, 198-204

Zaidi S. M., Banu N. (2004): Antioxidant potential of vitamins A, E and $\mathrm{C}$ in modulating oxidative stress in rat brain. Clin. Chim. Acta 340, 229-233

http://dx.doi.org/10.1016/j.cccn.2003.11.003

Received: April 4, 2011

Final version accepted: August 16, 2011 